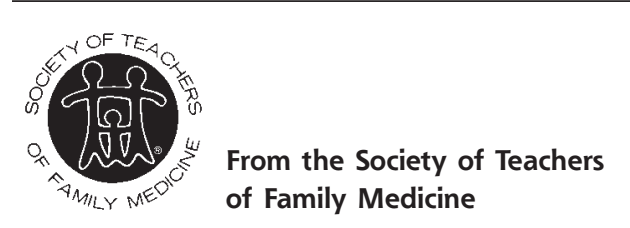

Ann Fam Med 2005;3:566-567. DOI: 10.1370/afm.414.

\section{STFM LAUNCHES VISION-DRIVEN ACADEMIC FUND-RAISING WORKSHOP AND FELLOWSHIP}

The Society of Teachers of Family Medicine (STFM) is launching an academic fund-raising workshop, Vision-Driven Fund-Raising 101 on December 2-3, 2005, in Indianapolis, Ind. The workshop is jointly sponsored by the STFM and the Family Medicine Education Consortium. Additional workshops will be held in the spring of 2006 for those who miss this opportunity to participate.

The 2-day workshop, designed for family medicine professionals, will introduce the knowledge and skills involved in using a "vision-driven" approach to fundraising. Workshop participants can expect to improve their understanding of the core issues, principles, and skills associated with obtaining financial support through the business, government, and philanthropic communities. Participants should have some experience with grant writing and a desire to develop a long-term, secure base of financial support for their work.

While fund-raising is often seen as a "necessary evil," the workshop will teach creative ways to understand the world of philanthropy, refine interpersonal skills, handle common problems, and invigorate enthusiasm for fund-raising. Fund-raising will be understood as a way to fulfill the donor's interests and desires, while advancing the recipients' goals and project plans.

The workshop is ideally suited for family medicine faculty responsible for developing financial support for their organizations, leaders seeking guidance about how to plan a fund-raising strategy to finance bold ideas and projects, and faculty members with grantwriting skills who want to develop new strategies to support their passions, projects, and interests.

This program supports STFM's New Partners Initiative (NPI). Through NPI, the leadership of STFM seeks to create relationships with foundations, corporations, government agencies, and groups that share common interests with the family of family medicine. To take advantage of these new opportunities, faculty will need the skills and abilities to work with philanthropic organizations.
As a result of participating in the workshop, participants will be able to:

1. Assess their current knowledge, skills, and abilities as vision-driven fund-raisers

2. Understand the core principles and practices of philanthropic fund-raising in our culture

3. Develop ideas that attract philanthropic support ("funding magnets")

4. Learn how to form a team to support their fundraising goals

5. Identify the philanthropic priorities of various types of donors

6. Cultivate and solicit significant gifts for their project(s)

7. Develop proposals that match the donor's interests and needs with a project's goals and objectives

8. Develop a network of contacts that will produce qualified donor prospects from various markets, ie, individuals, foundations, corporations, etc

9. Manage financial and organizational issues associated with receiving gifts, donations, and grants

The workshop registration fee is $\$ 475$ for STFM members and $\$ 700$ for non-STFM members (this includes 2006 STFM membership). This fee covers workshop handouts and meals during the 2-day meeting. Participants are responsible for their own travel, lodging, and incidental expenses. Pricing for multiple participants from a single organization is available at $\$ 450$ per registrant.

An optional fellowship experience is also being offered that includes participation in the academic fund-raising 2-day workshop and intensive, personalized coaching for a 1-year period following the workshop. The 1-year fellowship experience is intended for any mid-career to senior faculty and/or professional staff member with a clear fund-raising goal.

During the fellowship year, fellows will interact with the project faculty via e-mail, telephone conference calls, and, where possible, face-to-face meetings; each fellow will be coached by one or more of the fellowship faculty. Project faculty will provide guidance and information that will help the fellows succeed in their planning and project implementation.

Fellows will identify a project for which they intend to seek funding for their organization. A series of assignments will provide hands-on learning and will help the fellows develop relationships with funding sources that can support their projects. The fellowship will not offer certification or an advanced degree to recognize achievement. The goal of this fellowship and evidence of its success involves securing funding for the fellows' project.

The Fellowship registration fee is $\$ 7,500$ for STFM members and $\$ 7,725$ for non-STFM members. This 
fee covers the workshop fee and one year of coaching services. Fellows are responsible for their own travel, lodging, and incidental expenses. Fellows will be responsible for purchasing books and learning resources not distributed through the fellowship program. Discounted pricing is available for multiple fellows from a single organization.

This project is intended for leaders who are determined to succeed. With this in mind, fellows will be selected based on the project faculty's estimation of their likelihood to succeed as result of the fellowship experience. To submit an application for a fellowship experience, contact Vicky Evans, Vicky-tim@sbcglobal. net, 937-256-1073.

Workshop faculty will include Laurence Bauer, MSW, MEd, Family Medicine Education Consortium,
Inc, Dayton, Ohio; Stephen Bogdewic, $\mathrm{PhD}$, Indiana University; James Gillespie, CFRE, CommonWealth and Indiana University Center on Philanthropy, Indianapolis, Ind ind Alan Douglass, MD, Middlesex Hospital Family Medicine Residency, Middletown, Conn.

For more information about upcoming academic fund-raising workshops, visit http://www.stfm.org or contact Vicky Evans, Vicky-tim@sbcglobal.net, 937-256-1073.

For additional information, contact Mr Bauer, Laurencebauer@sbcglobal.net, 937-428-7866 or Roger Sherwood, CAE, STFM executive director, sherwood@ stfm.org, 800-274-2237, Ext 5400.

Traci Nolte, STFM Communications Director 